\title{
Addenbrooke's Hospital WHS
}

Cambridge University Hospitals NHS Foundation Trust

Ophthalmology Department

Box 41

Hills Road

Cambridge CB2 OQQ

Switchboard: 01223245151

Email: george.kong@addenbrookes.nhs.uk

\section{PARTICIPANT INFORMATION SHEET AND CONSENT FORM}

PRINCIPAL INVESTIGATOR:

\author{
Dr Yu Xiang George Kong \\ 10506 / Addenbrooke's Hospital \\ Hills Road, Cambridge, CB2 0QQ \\ Telephone: 01223245151
}

Prof Keith Martin

Telephone: 01223-216427 or 01223-274889

\section{Associate \\ INVESTIGATOR: \\ Participant Number:}

Full Study Title: Longitudinal assessment of visual field using iPad tablet computer for patients with glaucoma

Short Study Title: iPad Visual Fields Study

\section{Invitation and Summary}

We'd like to invite you to take part in our research study. Joining the study is entirely up to you, before you decide we would like you to understand why the research is being done and what it would involve for you. One of our team will go through this information sheet with you, to help you decide whether or not you would like to take part and answer any questions you may have. Please feel free to talk to others about the study if you wish and do ask if anything is unclear.

The first part of the Participant Information Sheet tells you the purpose of the study and what will happen to you if you take part.

The other part gives you more detailed information about the conduct of the study.

UK Patient Information Sheet and Informed Consent Form V1.2, dated 6th Jun 2016 (based on Model ICF v3.0 dated 18Dec2014)_EN

Cambridge University Teaching Hospitals Trust 
The this research is an innovative research aimed at testing whether the use of a popular consumer technology, the Apple iPad, is able to correctly detect visual field changes in patients with condition of glaucoma over time.

This Participant Information Sheet/Consent Form tells you about the research project. It explains the tests involved. Knowing what is involved will help you decide if you want to take part in the research.

Please read this information carefully. Ask questions about anything that you don't understand or want to know more about. Before deciding whether or not to take part, you might want to talk about it with a relative or friend.

Participation in this research is voluntary. If you don't wish to take part, you don't have to. You will receive the best possible care whether or not you take part. Participation in this research does not affect management of your eye condition in any way.

If you decide that you want to take part in the research project, you will be asked to sign the consent section. By signing it you are telling us that you:

- Understand what you have read

- Consent to take part in the research project

- Consent to have the vision tests that are described

- Consent to the use of your personal and health information as described.

You will be given a copy of this Participant Information and Consent Form to keep.

- You are under no obligation to take part in this study and should you decide not to participate, your future treatment and care will not be affected in any way.

- If you take part you can withdraw at any time without having to give a reason and your future treatment and care will not be affected in any way

- If you do decide to participate you will need to read this information sheet and sign a consent form to show you have agreed to take part.

\section{Participant Information - What is involved in this study?}

\section{What is the purpose of the Study?}

Glaucoma is one of the leading causes of irreversible blindness worldwide. The disease generally does not present symptoms early as it affects the side-vision or visual field first.

UK Patient Information Sheet and Informed Consent Form V1.2, dated 6th Jun 2016 (based on Model ICF v3.0 dated 18Dec2014)_EN

Cambridge University Teaching Hospitals Trust 
Current standard visual field testing machines such as a Humphrey visual field machine are not easily portable and come at a high cost. The Apple iPad however is a popular consumer technology that is portable, relatively low cost and has a high quality screen suitable for vision testing.

As part of the treatment of your eye condition you might have had visual field testing on a Humphrey visual field machine, where you are required to keep your eye focused on a point in the center and respond to a white spot shined in your side vision by clicking a button.

The aim of this study is to compare visual field testing perform using the Apple iPad against the Humphrey visual field machine over a period of 6 months.

The outcomes of this study will enable our institute to develop an innovative software for the Apple iPad that will allow visual field tests be conducted in areas with no access to the more expensive visual field machines, and also potentially in the future allow visual field tests to be done at home.

The research has been initiated by the study doctor, Dr George Kong.

\section{Why have I been invited?}

We have invited you to participate in this research study as you have high eye pressure or open angle glaucoma (an eye disease where your eye pressure is too high), or you could be invited as a control subject.

\section{Do I have to take part?}

No. It is up to you to decide. Your participation in this study is voluntary and you may refuse to participate or withdraw from the trial at any time without affecting the care you would normally be given and without penalty or loss of benefits to which you are otherwise entitled.

As part of this study, we will be testing your visual field using an Apple iPad machine. You cannot be identified from the images/photographs.

We will give you a copy of the information sheet and signed informed consent form to keep.

\section{What will happen to me if I take part?}

Your participation in the study will last for up to 6 months. This is made up of:

- Baseline visit

- 1 month visit

- 3 month visit

- 6 month visit

- At each visit you will have your usual visual field test using Humphrey visual field and then visual field test using iPad.

Enrolment in the study requires you signing a consent form which takes place after you have had a discussion with the study coordinator and have had time to read this information and have any questions answered. Collection of any data will only be undertaken once the consent has been signed.

UK Patient Information Sheet and Informed Consent Form V1.2, dated 6th Jun 2016 (based on Model ICF v3.0 dated 18Dec2014)_EN 
At the screening process, we will collect details of your current vision, and you will have a visual field test performed using Humphrey visual field machine. You will then have a visual field test using the iPad. Similar to the Humphrey visual field test, you will be asked to focus on a red fixation dot and press a button on the keyboard when you see a white spot appear in your side-vision. The software tests each eye separately and will take on average 5 minutes per eye, therefore will take about 10 minutes of your time.

In order to check if the iPad visual field software is able to produce the same outcome on two different occasions, you will also be asked to complete the same iPad visual field test again which takes 10 minutes of your time. This second session can be conducted after you have finished your clinic for the day, or we could arrange an appointment for you to return to have the test at your convenience within 8 weeks of enrolment into the study.

This study does not cause any harm or discomfort to you.

Your safety is our first priority and we will keep you informed throughout. In the case of any adverse event, the study manager will be notified and information recorded on a case report form. This incident report will be evaluated by the data safety monitoring committee and escalated to the human research ethics committee in the case of a severe adverse event.

This research project has been designed to make sure the researchers interpret the results in a fair and appropriate way and avoids study doctors or participants jumping to conclusions.

There are no additional costs associated with participating in this research project, nor will you be paid. You will not be reimbursed for travel, parking and other expenses associated with the research project visit.

The test result from the iPad visual field test will be used for the purpose of the study to validate the software program. It will not be used for any clinical decision making by the doctor who treats your condition.

\section{What will I have to do?}

If you decide to enrol in this study, you will have a visual field test using the Apple iPad after you have had a normal Humphrey visual field test. The study doctor will guide you through the software, including giving you instructions on what to do, where to keep your eye fixed and which buttons to press. The test takes 10 minutes.

As a study participant, you are responsible for following the study directions and those of your study doctor. This includes:

- Return on-time to the study centre for all study follow-up visits,

UK Patient Information Sheet and Informed Consent Form V1.2, dated 6th Jun 2016 (based on Model ICF v3.0 dated 18Dec2014)_EN 


\section{Expenses and Payment}

As a participant in this study, you will not be paid for taking part but will be reimbursed for expenses to cover your travel costs to and from each study visit on production of a receipt. Your study doctor will provide you more information.

\section{What are the alternatives for diagnosis or treatment?}

This study does not involve any treatment that is different from your usual glaucoma management. The test results from iPad does not influence any of the decision making process. You do not have to take part in this research project to receive treatment at this hospital. You will still have visual field test using the standard Humphrey visual field machine regardless of your participation in this study or not.

\section{What are the possible disadvantages and risks of taking part?}

We do not envisage any side-effects or adverse reactions to occur as result of your participation in doing a 10 minute visual field test on the iPad.

It does however require the generous donation of your time for the initial 10 minute session and possibly a second 10 minute session if it does not inconvenience you greatly.

\section{What are the possible benefits of taking part?}

We cannot guarantee or promise that you will receive any benefits from this research. The results from your participation could lead to development of innovative software that one day would allow home monitoring of visual field and also to help provide glaucoma care in rural and remote communities.

\section{What Happens When The Research Study Stops?}

After the research project period ends, you will continue to be treated in the glaucoma clinic. The frequency of follow up visits will depend on your clinical situation and the stability of your eye condition.

If you wish, we will provide you a summary of the results of the study once the research project has completed. This will be given to you in a written format at your follow up visit or mailed to you if you prefer. It is estimated that the results may take 12-18 months after the study completion to be analysed and made available to the participants. 


\section{Further Supporting Information:}

\section{What if relevant new information becomes available?}

The study doctor will inform you of any new information about the study medicine that might develop during the course of this research and might influence your willingness to participate in the study. If you decide not to continue, your study doctor will make arrangements for your care to continue. If you decide to continue in the study, your study doctor may ask you to sign an agreement outlining the discussion or an entirely new informed consent form.

\section{What will happen if I don't want to carry on with the study?}

If you decide to withdraw from the project, please notify a member of the research team before you withdraw. Withdrawal from this study does not alter how you are managed by your doctor in any way; you will need to continue seeing your glaucoma doctor. It is important to have your eye condition monitored as it may progress to loss of vision if left untreated.

If you do withdraw your consent during the research project, the study doctor and relevant study staff will not collect additional personal information from you, although personal information already collected will be retained to ensure that the results of the research project can be measured properly and to comply with law.

\section{What if there is a problem?}

Complaint - If you have a concern about any aspect of this study, you should ask to speak with the researchers who will do their best to answer your questions (telephone number 01223-216427 or 01223-274889). If you remain unhappy and wish to complain formally, you can do this through the NHS Complaints Procedure. We recommend that you obtain a copy of the hospital's complaints procedure or policy if you intend to make a complaint.

If you suffer any injuries or complications as a result of this research project, you should contact the study team as soon as possible and you will be assistedwith arranging appropriate medical treatment. It is however no foreseeable harm resulting from performing visual field test on the iPad.

If you have any complaints or concerns about the study, you should raise this immediately with the study investigators or trial coordinator. If you prefer, you may also direct any concerns to the Addenbrooke's Hospital patient liaison team.

Your safety and welfare is our priority and we take all complaints seriously and all adverse events will be fully investigated as per our safety committee guidelines. 


\section{Will my taking part in this study be kept confidential?}

Your identity and your medical information will be kept confidential. You will not be able to participate if you do not provide consent.

Personal information such as your name, contact information, age, gender, information on your medical history, will be collected and recorded as part of the study. Some of this information can be regarded as sensitive data and will only be used for clinical research purpose. Your study doctor will keep these records in paper or electronic format.

All personnel accessing your records are required to respect your confidentiality at all times.

To ensure privacy, your full identity will not appear on any of the study data or samples collected by the sponsor or its service provider for their analyses. A unique patient number for the study will be used to code any information about you that leaves the study site. Only the study doctor and authorised personnel will be able to connect this code to your name, by a list that will be kept securely by the hospital for a period of at least 15 years, according to applicable laws.

Study data will be transferred into a computer database and processed to allow the results of this study to be analysed and reported or published. If the results of the study are published, your identity will remain confidential.

A report of the results of this study may be published or sent to the appropriate health authorities, but your name will not be disclosed in these documents. Appropriate care will be taken to maintain confidentiality of your medical records and personal health information.

You have the right to access, through your study doctor, all the information collected about you and, if applicable, ask for corrections.

\section{Authorising the use of medical information}

This clinical study may only be performed by collecting and using your medical information. Data protection laws give you the right to control the use and disclosure of your medical information. Therefore, by signing this form you specifically authorise your information to be checked, transferred and processed as follows:

- Authorised representatives of the sponsor and regulatory authorities' inspectors may review your medical information by direct access to your medical records.

- Study data, including your coded medical information, may be used and shared for legitimate study and scientific purposes,

- Study data may be transferred to other countries for processing, including countries not covered by the same level of data protection legislation as the UK.

A description of this clinical trial will be available on http://www.ClinicalTrials.gov, as required by U.S. Law. This Web site will not include information that can identify you. At most, the Web site will include a summary of the study results. You can search this Web site at any time.

UK Patient Information Sheet and Informed Consent Form V1.2, dated 6th Jun 2016 (based on Model ICF v3.0 dated 18Dec2014)_EN

Cambridge University Teaching Hospitals Trust

Page $\mathbf{7}$ of $\mathbf{1 1}$ 


\section{Use of Images/Photographs/Videos}

No images, photograph or videos will be taken of you as part of the study.

\section{Involvement of the General Practitioner/family doctor}

Your doctor (general practitioner) will not be be notified of your involvement in this study as involvement in this study will not affect your medical treatments.

\section{What will happen to any samples I give?}

No test samples will be collected in this study.

\section{Will any genetic tests be done?}

There will be no genetic tests done as part of this study.

\section{What will happen to the results of the research study?}

The study sponsor may use results of this study in reports of the study or for scientific presentations or publication. You will not be identified by name, picture or any other personally identifying information.

\section{Who is organising and funding this research?}

This research project is being conducted by the Addenbrooke's Hospital. The principal investigator is Dr George Kong.

No member of the research team will receive a personal financial benefit from your involvement in this research project (other than their ordinary wages).

\section{Who has reviewed this study?}

All research in the NHS is looked at by independent group of people, called a Research Ethics Committee to protect your safety, rights, wellbeing and dignity.

\section{Further information and Contact details}

You are encouraged to ask the study doctor any questions about this study or this consent form, and you should receive satisfactory answers to your questions. If you experience any research-related injuries during the study, you should contact Dr George Kong 01223245151 
If you have any questions concerning your rights as a research patient, you should contact the Local Patient Advice and Liaison Services (PALS). To find the nearest PALS office from your home, you can use the following link: http://www.pals.nhs.uk/officemapsearch.aspx

Thank you for reading the information and considering taking part in this study.

UK Patient Information Sheet and Informed Consent Form V1.2, dated 6th Jun 2016 (based on Model ICF v3.0 dated 18Dec2014) _EN

Cambridge University Teaching Hospitals Trust 
UK Patient Information Sheet and Informed Consent Form V1.2, dated 6th Jun 2016 (based on Model ICF v3.0 dated 18Dec2014) _EN

Cambridge University Teaching Hospitals Trust

Page $\mathbf{1 0}$ of $\mathbf{1 1}$ 


\section{Addenbrooke's Hospital WHS}

Cambridge University Hospitals NHS Foundation Trust

UK Patient Information Sheet and Informed Consent Form V1.2, dated 6th Jun 2016 (based on Model ICF v3.0 dated 18Dec2014) _EN

Cambridge University Teaching Hospitals Trust

Page 11 of 11 